\title{
Sanat Antropolojisinin Sanat ve Sanat Eleştirisi Açısından Önemi
}

\author{
Importance of Art Anthropology in Terms of
}

\author{
Art and Art Criticism
}

\section{Ferhunde Küçükşen Öner*}

\section{Özet}

Sanatın varlığı insan ve toplum ilişkisinin boyutlarını göstermesi açısından anlamlıdır. Bu boyutlar sanatın kültürle olan bağını kuran dinamiklerden biridir. Sanat eleştirisi, sanatsal değerlerin, sanat eserinin ortaya çıkışındaki nedensellik ve anlamlandırma sürecinin kaydını tutarak sanat tarihine dolayısıyla kültür tarihine katkıda bulunan kurumlardan biridir. Antropoloji de insan ve toplum ilişkisinin geçirdiği değiş̧imlerin kaydını tutarken kültürün kavramsal ve pratik açılardan nasıl ortaya çıktığını ve geliştiğini inceler. Bu nedenle sanat ve sanat eleştirisinin, antropolojinin verilerinden yararlanması kaçınılmazdır.

Sanat eserlerinin ortaya çıkış sürecinde pek çok farklı disiplin, kendiliğinden ya da sanatçının bilinçli tercihiyle etkili bir kaynak olarak kullanılabilmektedir. Sanat eleştirisinin niteliklerinden biri de sanat eserinin ortaya çıkışında etkili olan bu disiplinleri keşfederek sanat eserine estetik ve toplumsal anlam kazandırmaktır. Bu makalede sanat eserinin ortaya çıkışında ve sanat eleştirisinin bu eseri anlamlandırma sürecinde antropolojinin oynadığı rol üzerinde durulacaktır. Öncelikle antropolojinin sanat ve sanat eleştirisi açısından önem arz eden özelliklerinden bahsedilmiştir. Sonrasında sanat ve sanat eleştirisi açısın-

* Dr. Öğr. Üyesi, Bartın Üniversitesi Eğitim Fakültesi, Güzel Sanatlar Eğitimi Bölümü. foner@bartin.edu.tr 
dan antropolojinin neden önemli olduğuna değinilmiş, antropolojinin insanın ve toplumun değişim seyrinin kaydını tutma özelliğinin sanat ve sanat eleştirisi açısından önemi anlatılmıştır.

Anahtar sözcükler: sanat, sanat eleştirisi, antropoloji, sanat antropolojisi, disiplinlerarasılık

\begin{abstract}
The existence of art is important since it demonstrates the aspects of people and social relations. These aspects are one of the dynamics connecting art with culture. Art criticism is one of the institutions that contributes to the history of art, and thus to the history of culture by keeping the record of the artistic values, the causality and the sense making process in the emergence of the work of art. Also, anthropology examines how the culture has emerged and developed from conceptual and practical aspects, while keeping the record of the changes undergone by people and social relations. For this reason, it is inevitable for art and art criticism to make use of the anthropological data.

Many different disciplines may be used as an effective source by itself or by the informed choice of the artist in the process of the emergence of art works. One of the qualities of art criticism is to add aesthetic and social meaning to the work of art by discovering these disciplines which are effective in the emergence of art work. This article shall focus on the role of anthropology in the emergence of art works and in the process of sense-making of this art work by criticism. First, the important characteristics of anthropology in terms of art and art criticism shall be mentioned. Afterwards, why the anthropology is important in terms of art and art criticism shall be mentioned and the importance of anthropology's characteristics of keeping the record of the change of the people and the society shall be explained in terms of art and art criticism.
\end{abstract}

Keywords: art, artcriticism, anthropology, artanthropology, interdisciplinarity

\title{
Giriş
}

En geniş anlamıyla “insanbilim”, “insanla ilgili düzenli bilgi” anlamına gelen Antropoloji sözcüğünün kökeni "İnsan anlamına gelen 'Anthropos' ile düzenli bilgi anlamında olan 'logos'a dayanır. Antropoloji, insanın dünü, bugünü ve yarınını sosyo-kültürel, biyolojik, morfolojik (dilbilimi, biyoloji, astronomi) ve fiziksel açıdan ele alan çok disiplinli bir bilim dalıdır" (Konak 2006: 1). Bu tanımlama antropolojinin yalnızca insanın geçmişiyle ilgilendiğine dair yaygın ve yanlış kanının da düzeltilmesine katkı sunabilir. Zira 4.5 milyar yıl öncesinin primitif şartlarda yaşayan insanı da bugünün uzay araştırmaları yapan modern insanı da antropolojinin araştırma alanı içindedir. "Antropoloji, insanın ilgili olduğu, yaptığ bütün insan ırklarını inceler. Antropoloji, insanın yaptıkları, davranışları inançları, görüş 
ve görünüşleri ile ilgilidir. İnsanı sonsuza varan çeşitliliği içinde inceler. İnsanın ilk kez nasıl ve ne zaman ortaya çıktığını, geçmiş zamanlarda yeryüzünde yaşamış insanların bizden farklı olup olmadığını araştırır. Yabancı ülkeleri ve bize aykırı gelen yerlileri araştırarak insanların nasıl giyindiğini, beslendiğini, nasıl evlendiğini, çocukların nasıl oynadığını, büyücülerin nasıl çalıştığını öğrenmeye çalışır. Yitik uygarlıkların ticaret yollarından çağdaş toplumların işçi sendikalarına değin her şeyi inceler... Tibetli keşişleri mi yoksa pop müziğini mi merak ediyorsunuz? Antropoloji doğru yanıtları bulmanıza yardımcı olabilir" (Wells 1984: 9).

Antropoloji, birey olarak insanla ilgilenmez. İlgisi grup içinde yaşayan insan ve bu insanın yaşam pratikleri, davranışlarıdır. Daha doğru bir söyleyişle antropoloji, insanı, yaşadığ

Antropoloji bu kapsayıcı niteliğinden dolayı bazı bilim adamları tarafından taç bilim olarak kabul edilirken bazılarınca da "artık bilim" olarak adlandırılmakta ve insa$\mathrm{n}$ ı toplumsal bir varlık olarak inceleyen farklı disiplinlerin varlığını ön plana çıkararak zaman zaman göz ardı edilmektedir. Oysa Antropoloji, incelediği konular ve kendisine özgü olan yöntemleri ile diğer sosyal bilim dalları arasında özel bir yere sahiptir. Antropolojiyi insanla ilgili olan diğer bilim dallarından ayıran en büyük özellik antropolojinin saha çalışmalarına verdiği önemdir. Gerek arkeolojik kazılar gerekse çeşitli kültürlerin içine girerek, onlarla yaşayarak ve onları gözlemleyerek incelemeler yapar.

Antropolojinin üzerinde durduğu ve günümüzde de geçerli olan bazı sorular:

" 1 - İnsanlar ve toplumlar neden birbirine benziyor?

2- İnsanlar ve toplumlar neden birbirine benzemiyor?

3- İnsanlar ve toplumlar neden ya da nasıl değişiyor?" (Güvenç 1984: 26) dur. Modern antropoloji bilimi, bugün de bu sorular üzerinde çalışmalar yapmaktadır.

Antropolojinin, sözcük olarak kökeni Aristoteles'e (M.Ö.388-322) kadar gitmektedir. "Bu sözcük büyük olasılıkla M.Ö. 4.yüzyıl bilgini Aristoteles'in insan tanımından kaynaklanmaktadır. Karşılaştırmalı anatomi ve fizyolojinin kurucusu kabul edilen Aristoteles insanı evrenin bir parçası olarak incelemiştir" (Güleç 1994:22).

"Tarihin kurucusu olarak tanınan Herodot'u Çiçero'ya ve bazı Batı kaynaklarına göre, antropolojinin (insanbilimi) de kurucularından saymak gerekir. Çünkü Heredot, Akdeniz çevresindeki ülkeler konusunda görüp işittiklerini yazmakla yetinmez; bu ülkelerde yaşayan insanların tarih açısından niçin farklı olduğu sorusuna güvenilir bir cevap arar. Heredot, bu toplumların davranışlarında, törede, teknoloji ve politika düzeylerinde nasıl farklı olduklarını anlatır, başka bir deyimle, onların kültür'lerini inceler; tarihi olayları kültür farklarıyla açıklamaya çalışır; böylece, toplumla tarih arasındaki karşılıklı ilişkiyi gören ve değerlendiren ilk düşünürler arasında yer alır” ( Güvenç 1984: 4).

Antropoloji'nin modern anlamıyla kullanılması ise Keşifler Çağı'na kadar gitmektedir. "Antropoloji modern anlamiyla ilk olarak Hundt'1n Antropologeion' unda (1501) anatomiyle ilgili olarak ve Capella(Kapela)'nın L'Anthropolegia'sında (1533) ise kişisel özelliklerle ilgili olarak ele alınır" (Güleç 1984: 22).

XVI. yüzyılda Montaigne, Denemeler' inde insanlar arasındaki gelenek, görenek ve 
töre farklılıklarını inceler. XVII. Yüzyıl'da Isaac de la Peyrere Fransa'da bulunan bazı taş parçalarını inceleyerek bunların ilk insanlara ait olduğunu ileri sürer ve bununla ilgili bir kitap yazar. O dönem için ilk insan Adem'den başka insanların varlığını düşündüğü için kitabı yakılır. Yine aynı yüzyılda Hobbes, eski insanlar üzerindeki araştırmalarıyla; XVIII. Yüzyıl'da filozof Locke insan davranışları ve soya çekim üzerine yaptı̆̆ araştırmalarla; İsveçli biyoloji bilgini Carl Linnaeus insan ırklarını ayıran çalışmalarıyla; Montesquieu ülkeler arasındaki farklılıkları incelemesiyle; Voltaire insanın uygarlık basamaklarını incelemek üzere yaptığı araştırmalarla; XIX. Yüzyıl'da Dr. Bastian, etnolog Ratzel, hukukçu Lewis H.Morgan ve Henry Sumner Maine, Charles Darwin'in Türlerin Kökeni adlı denemesinde ele aldığı Evim Teorisi ve onu destekleyen Thomas H. Huxley'in Insan'ın Türeyişi adlı kitabıyla antropoloji bilimi gelişerek bugünkü halini alır. Bu gelişmede doruk noktası XIX. Yüzyıl'dır. Çünkü bu yüzyılda yapılan çalışmalar sonucu ilk defa tarih öncesi insanlara ait iskeletler ve fosiller bulunmaya başlar. $\mathrm{Bu}$ buluşlarla birlikte antropoloji çalışmaları derinlik kazanarak, yukarıda adı geçen bilim adamlarının teorileri sağlam bulgularla desteklenmiş olur.

\section{Sanat antropolojisi:}

Antropolojinin araştırma sahası sanatın toplumsal boyutlarıyla -kültür, dil, din, siyaset vb.- doğrudan ilişkilidir. Bu boyutlar en geniş anlamda kültür kavramı çatısında birleştirilebilir: "Sanat (...) tüm etkinlikleri gibi varoluşun maddesel koşullarından etkilenen özerk bir etkinliktir; bir bilgi biçimi olarak kendi gerçeği ve kendi sonucu vardır. Siyasetle, dinle ve bizim insan alınyazımıza tepki gösteren tüm öteki biçimlerle gerekli ilişkileri vardır. Ama bir tepki biçimi olarak ayrıdır ve uygarlık ya da kültür dediğimiz şeyin bütünleşme sürecine katkısı vardır" (Baynes 2002: 31).

Sanat ve Antropoloji'nin insanın tarihsel süreç içerisinde gelişimini incelerken ortak noktalardan baktı̆̆ çok yer bulunmaktadır. Bunlardan en önemlisi sanatı, kültürleri oluşturan en önemli unsurun insan olduğu gerçeğine her iki disiplinin de yaptığı vurgudur. Yani iki disiplinin de ilk ve en önemli muhatabı 'insan'dır. Antropoloji insanın gelişiminde "kültür" gibi -insanın gelişimini somut örneklerle gösteren- önemli bir olgudan faydalanıyorsa "sanat"la dolaylı değil doğrudan ilgili olmak zorundadır. Sanatın diğer disiplinlerle kurduğu ilişkilerin -örneğin sanat ve sosyoloji gibi iki disiplinin kesiştiği noktada duran sanat sosyolojisi- boyutu antropolojiyle kurduğu ilişkiye benzer bir yapılanma içerir ve bağımsız disiplinlerin oluşmasından öncesine dayanır.

Sanat antropolojisi çalışmaları sosyal/kültürel antropoloji bilimi ortaya çıktığından ve 1879 'da ilk resimli mağara (Altamira mağaras1) bulunduğundan bu yana tıpk1 etnoloji gibi adı konulmadan yapılmaktadır. İnsan toplumlarının kültürünü araştıran bir bilimin o kültürü oluşturan en büyük etmenlerden biri olan sanatı incelememesi mümkün değildir. Son yıllarda yalnızca sanat alanına eğilerek, inceleme yapan araştırmacıların sayısı artmaktadır. Örneğin İngiliz tasarım ve teknoloji profesörü Ken Baynes ilk baskısı 1975 yılında yapılan Toplumda Sanat adlı kitabının Geçmişte, Günümüzde ve Gelecekte Tapınma adlı bölümünde insan kültürünün temel yapı taşları olan din ve sanat ilişkilerini 
sorgulayıp sanat antropolojisi alanında örnek sayılabilecek bir çalışmaya imza atmıştır (Baynes 2002: 75-97). Ayrıca sosyal/kültürel antropoloji alanında çalışan hemen bütün antropologlar kültürü incelerken sanat eserleri üzerinde de durur. Farklı disiplinleri inceleyen bilim adamları da sanatsal yaratıcılıkla ilgilenirken antropolojinin toplumsal boyutuyla temas kurar: "Psikolog sanatsal yaratıcılıkla ilgili zihinsel süreçleri araştırmaya soyunabilir. Bu süreçler özünde her yerde aynı olmasına rağmen yapılması gereken şey sanatçıyla yalnızca bir yaratıcı olarak ilgilenmek değil, aynı zamanda sanatçının yaşadığ kültürel alandaki etkisini ve üretilen eserin kendi türdeşleri üzerindeki tesirini irdelemek olmalıdır" ( Boas 2017: 11).

Kültür, hem sanatın hem de antropolojinin ortak alanı olarak karşımıza çıkmaktadır. Sanat, sanat tarihi ve sanat eleştirisi, kültüre insanın içselleştirilmiş etkinliği olarak bakarken Antropoloji insanın gelişim sürecinde oynadığı rol bağlamında bakar. Sanat antropolojisi bu iki disiplinin farklı bakış açılarını birleştiren bir çıkış noktası olarak düşünülebilir. Levi-Strauss, Japonya'da Raku denilen seramik sanatının ortaya çıkışında Japonların arkaik dönem sanatına olan ilgisinin etkili olduğunu söyler: "Illk konferansımda Avrupa'nın "ilkel” denen sanatlara ilgi göstermesinin tarihinin yüzy1lı bulmadığını kaydetmiştim. Japonya'da ise benzer bir ilgi, Japon estetlerin Koreli mütevazı köylülerin elinden çıkma çömleklere, eserlere, v.b. duyduğu tutku dolayısıyla ta XVI. yüzyıla dek uzanır. Japonlarda işlenmeden bırakılmış malzemelerden, pürüzlü dokulardan, imalat hatalarından bozuk ya da asimetrik biçimlerden, kısacası arkaik üslupların büyük teorisyeni Yanagi Soetsu'nun "kusurlu olanın sanatı" dediği şeylerden duyulan zevk bu tutkuyu teyit eder. İlk yaratıcıları tarafından bilinçli bir şekilde üretilmemiş olan bu "kusurlu olanın sanatı" Japonya'da raku denen seramik sanatını, Koetsu gibi usta bir çömlek sanatçısının cüretkar sadeleştirmelerine, grafik ve plastik sanatlar alanlarında da Sotatsu ve Korin gibi ressam ve deoratörlerin eserlerine ilham vermiştir"(Lévi-Strauss 2014:95). Antropolojinin sunduğu veriler yeni sanat dallarının ortaya çıkmasında etkili olmuştur. Bu noktada sanat antropolojisinin varlı̆̆ yalnızca bilimsel araştırmalar için değil sanatın varlığı ve gelişimi için de önemli hale gelir.

Geçmişte tercih edilen ve anlamlı bir çalışma alanı olmaktan uzak görülen sanat antropolojisi, disiplinlerarasılığın bilimsel metodolojide nedensellik ilkesini oluşturmada vazgeçilmez kabul edilmesiyle önemini artırmıştır. Özellikle kültürel çalışmalarda sanat antropolojisinin varlığı hem nedensellik belirlemede hem tarihsellik ilişkisi kurmada öncelikli başvuru alanlarından biridir. "Öyle ki bugün ortam odaklı sanatta bir kurumun ya da topluluğun etnografik haritasının çıkarılması ana biçim haline gelmiştir" (Güngör 2013: 11). Bugünün toplumsal ortamı ve onun yansımalarının kaydını tutan sanatın anlamlı hale gelebilmesi adına sanat antropolojisi çalışmaları önemini artırmıştır: "Güzel dışında yepyeni bir estetik peşinde koşan güncel sanat, yaşamı sanatın merkezine alan, toplumsal değişim, genetik kırılmalar, yaşamdaki dayatmalar gibi bugünün insanının yaşam alanı oluşturan hemen her konuyu malzeme yaparken, sosyoloji, psikoloji, antropoloji, sosyal politikalar gibi diğer disiplin alanları içerisinde ele alınan konularla da bağlar kurmaktadır" ( Koç 2017: 2261). 
Ayşe Güngör, Alfred Gell'in, antropolojinin bir sosyal disiplin olduğu vurgusundan hareketle sanatın toplumsal boyutunu oluşturan dinamiklerden biri olduğunu söyler ve sanat eserlerini değerlendirme işlevini antropolojiden de yararlanması gereken eleştiri kurumunun üstlenmesi gerektiğini belirtir: "Sanat antropolojisi sanat üretiminin sosyal içeriğine, dağıtım döngüsüne ve kabulüne, odaklanır; çeşitli sanat eserlerinin değerlendirilmesi ise, eleştirmenin görevidir. Gell bu durumu örneklemek adına, antropolojik sanat teorisinde, sanat eserlerinin, 'kişiler' ya da 'sosyal temsilciler' olarak düşünülebileceğini söyler. Antropoloji yaşam sahnesinde olanı, yaşamın içeriğinde inceler, bu yüzden antropolojik sanat teorisinde eserler, insanlardan, sosyal ilişkilerden bağımsız biçimde düşünülemez" (Güngör 2013: 7-8; Gell 1998: 3). Sanatla toplum arasındaki ilişkinin boyutları sanat eserinin ortaya çıkışında ve anlamlandırma sürecinde önemli bir rol oynar. Bu bağlamda antropolojinin sanat eleştirisi açısından taşıdığ kadar artmıştır.

\section{Sanat antropolojisinin sanat ve sanat eleştirisi açısından önemi}

Sanat ve Antropoloji'nin bir disiplinin bütünlüğü içerisinde bir araya geldiği zamanın başladığı noktayı bulmak güçtür. İnsanı inceleyen Antropoloji’nin sanatı gündemine alması, sanatın sosyolojik boyutuyla Antropoloji'nin çalışmalarından haberdar olması doğal bir süreç halinde başlamış ve gelişme göstermiştir.

Sanat üzerine araştırmalar, tartışmalar, konuşmalar yapılmaya başlandığından ve ilk sanat eserleri bulunduğundan beri, insanlar tıpkı insanın kökenini merak ettikleri gibi sanatın da kökenini araştırmışlardır. Bu konuyla ilgili sanat, bilim ve felsefe alanlarından insanlar farklı görüşler ileri sürülmüştür. Bazıları sanatın doğuşunu din ve büyüye bağlarken bazıları da sanatın kökeninin oyun ya da öykünme olduğunu söylemektedir. $\mathrm{Bu}$ görüşleri bilmek sanat ve sanat eleştirisi açısından antropolojinin önemini kavramak adına anlamlıdır.

Ernst Fischer, sanatın ortaya çıkışını doğayla mücadele düzlemine bağlar: "İnsan varoluşunun ta kökündeki bu büyü -güçsüzlük duygusu ile birlikte güçlülük bilincini, doğa korkusu ile birlikte doğaya üstünlük sağlama yeteneğini yaratma- her türlü sanatın başlıca özüdür. İnsanların kullanabilmesi için taşa şekil veren ilk alet yapıcı, ilk sanatçıdır..."(Fischer 1995: 34) Bu düzlemin güzellikten önce 'yaşama savaşı' için kullanılan bir argüman olduğunu da ekler: “İnsanlığın başlangıcında sanatın 'güzellik'le uzun boylu bir ilintisi yoktu, estetik kaygısı ise hiç yoktu: insan topluluğunun yaşama savaşında kullandığı büyülü bir alet bir silahtı sanat" (Fischer 1995: 36-37).

Aristoteles, "öykünme tüm insanlarda çocukluktan itibaren doğaldır. İnsanın öteki aşağı hayvanlar karşısındaki üstünlüğü dünyada en öykünücü yaratık olması ve önce öykünmeyle öğrenmesidir" (Cassirer 2005:130) diyerek sanat ve öykünme arasında doğal bağlar kurar ve insan olma farklılığının sanatla göründüğünü imler.

Kagan, sanatı, inanç-insan-hayat ilişkisinin dinamiklerinden biri olarak tanımlar: “ Hiç kuşkusuz, sanat, dinsel bilinçten, 'eski' toplumdaki büyüden ortaya çıkmamıştır... Sanat ile din birçok başlıca ilişkiler bakımından birbirlerinden ayrılırlar. Her şeyden 
önce, imgesel bilgiden ortaya çıkmış olan din, sanatsal hayal gücünün getirdiklerini gizemleşmiş olarak yorumlar" (Kagan 1993:226-227).

Heidegger de 'dil'in sanatın kökenlerini bulmada en etkili unsurlardan biri olduğunu düşünür: "Heidegger, şiirin eylem alanının dil olduğunu, şiirin özünü dilin özüyle birlikte düşünüp, varoluşun ve bütün nesnelerin özünün kurucusu olarak adlandırmak gerektiğini ifade eder" (Eren 2006: 1).

Sanatın kökenine dair görüşler bu çalışmanın sınırlarını aşacak ölçüde çoğaltılabilir. Ancak doğa, inanç, dil, öykünme vb. köken yaklaşımlarının sanatı ortaya çıkaran etmenler olduğu kadar her çağ/dönemde sanatın devamını sağlayan ve anlam kazanmasına zemin oluşturan dinamikler olduğu söylenebilir. Bu nedenle sanatın olduğu kadar sanat eleştirisinin de antropolojiden yararlanma süreci geniş zamana yayılmıştır. Geçmiş, şimdi, gelecek düzlemini kapsayan bu yayılma, sanat kuramlarının çerçevesini belirlerken de etkilidir. Örneğin edebiyat sanatında ortaya çıkan ve zamanla farklı disiplinlerin de dâhil olduğu 'yeni tarihselci' yaklaşım, "aynı tarihsel döneme ait yazınsal ve yazınsal olmayan metinlerin paralel okunuşuna dayanan" (Kolcu 2010:348) bir eleştiri yöntemidir. Köklerin antikçağa kadar dayandırılmasından yana olan bu yaklaşım, farklı disiplinlerin olanaklarından yararlanmayı da önemser. Yeni tarihselci eleştiri bağlamında sanat eserini anlamlandırmak için antropolojinin verileri de anlamlı hale gelir.

Antropolojinin dalları ve çalışma alanları da sanat eleştirisi için süreç içerisinde farklı anlamlar kazanarak önemini korumuştur. Antropolojinin ilgili olduğu alanlar, değişim ve yenilik ilkesini daima benimseyen sanat ve sanat eleştirisi için farklı nedensellikler üzerinden anlam kazanmıştır. Örneğin sosyal/kültürel antropoloji sanat eleştirisi için başlangıçta sanatın kökenleri hakkında bir yargıya varmak üzere önemli bilgiler sunarken, zamanla sanatın değişim sürecini takip etmek için başvurduğu bilgi alanlarından birine dönüşmüştür. Sosyal/Kültürel antropoloji, primitif ya da çağdaş bütün toplumların kültürlerini inceleyen bir disiplindir ve yalnızca geleneksel yaşayan kabileler ya da eski topluluklarla ilgilenmez. Günümüz kozmopolit şehirlerinde yaşayan çağdaş insan da sosyal antropoloğun araştırma alanı içindedir. Dolayısıyla sosyal/kültürel antropoloji, insanın kültürel varlığını geçmişten bugüne ortaya koyarken sanat eleştirisinin insan ve toplum ilişkisini gözler önüne seren, kökenle başlayıp gelişim ve değişim düzleminde aktardığı, kimi zaman geçmiş-şimdi bağıntısını kurduğu bakış açısına katkıda bulunur. Bu katk1 'şimdi'ye uzanan bütün sanat tarihi serüvenini anlamlandırma sürecinde antropolojinin varlığını anlamlı kılar.

Sanat eleştirisi, sanat eserini ortaya çıkaran dinamikleri 'şimdi' de sentezleyen bir işleve sahiptir. Bu nedenle güncel olanla daha çok ilgilenir. Ancak güncel olanı ortaya çıaran bütün nedensellikler doğrudan eleştirinin ilgi alanına girer. Bu nedenle antropolojinin sunduğu veriler, sanat eleştirisinin güncel sanatı anlamlandırma sürecinde etkilidir. Örneğin 1967'de İtalyan sanat tarihçisi ve eleştirmeni Germano Celant tarafindan adlandırılan 'Arte Povera' (Fakir Sanatı)nın temelinde dönemin ruhuna uygun kavramsal yaklaşımlar söz konusudur ve aslolan çöp atıkları, kırık cam parçaları, işlenmiş veya işlenmemiş metaller, toprak, su, kömür, ağaç yaprakları kısacası doğadan gelen 
her türlü maddeyi sanatın malzemesine dönüştürmektir. Arte Povera sanatçılarının kullandığı malzemeler, dahası doğanın varlı̆̆ını imleyen bu yaklaşımla insanlığın gelişim sürecinde gelinen noktayı yani kendi yaşadıkları dönemi eleştirdikleri söylenebilir. Tam da bu noktada antropolojinin verilerinin sanat eleştirisi ile kesişmektedir. Bu bağlamda insanlığın gelişim sürecini inceleyen antropolojinin sunduğu veriler Arte Povera'nın ortaya çıkışında etkili olmuştur ve sanat eleştirmeni de bu veriler ışığında güncel sanatı yorumlayabilmiştir.

Sanat eleştirmeni, antropologlara özgü bakış açısı ile geçmişten günümüze farklı kültürlerin sanatlarını derinlemesine inceleyerek, bugünün sanatına ve sanatçılarına yol gösterici olabilir. Günümüz sanatına, süreç boyunca insanlığın -dolayısıyla sanatın- değişimine dair bilgiler ışığında ulaşabilir.

Örneğin 20. yüzyılın başlarında fovistler, ekspresyonistler, kübistler, dadacılar adeta bir moda gibi eski sanatı incelemişler, eski sanat eserlerinden koleksiyonlar oluşturmuşlar ve bu akımların sanatçılarından birçoğu sanat motifleri içeren eserler vermişlerdir. Geçmişten yararlanması yalnızca geleneğin sanattaki yeri bağlamında değerlendirildiğinde bu sanatçıların ortaya koyduğu yapılanma geleneğin eleştirisini de barındırmaktadır. Eleştiri mekanizması antropolojinin sosyoloji ile kurduğu disiplinlerarası ilişkiden yararlanarak sanatın geldiği noktaya anlam kazandırabilir.

Son dönemlerde sanat eserinin ortaya çıkışına dair tartışmaların varlı̆̆ 1 da sanat eleştirisi ile sanat antropolojisi arasındaki ilişkiyi göstermesi bakımından anlamlıdır. Sanat eserini ortaya çıkaran eklektik yapının tartışıldığı son dönemlerde sanatın her unsuru bir üretim malzemesine dönüştürmesinin bir taraftan sanat eleştirisinin antropoloji ile kurduğu ilişkinin bağlarını güçlendirdiği diğer taraftan bu ilişkinin sınırlarını ortadan kaldırdığı da görülmektedir. Larry Shiner, sanatın oluşumunu zanaattan ayrılma sürecine bağlı olarak anlattı̆̆ı Sanatın İcadı Bir Kültür Tarihi adlı çalışmasında sanat eleştirisi ile antropoloji arasındaki ilişkinin bugünün sanat ortamına benzer bir yapıyla ortaya çımasından bahseder. "Bir Baule oymacısı danslarda giyilmek üzere ürkütücü bir mihver maske yaparken bununla köyünü korumayı amaçlardı. Hâlbuki aynı maske bu bağlamından soyutlanarak sanat müzesindeki mahfazaya konduğu, bir gösteriş kitabı için fotoğrafı çekildiği yahut modern sanat söylemine oturtulduğu anda farklı bir anlam sistemine girmiş olur... Susan Vogel'in 1997 y1lındaki örnek sergisi Baule: Afrikalı Sanat, Batılı Göz nesneleri bağlama oturtmakta ve farkll1ık meselesini ortaya atmakta o denli başarılıydı ki kimi eleştirmenler serginin bir antropoloji sergisini andırdığından şikâyet ediyordu" (Shiner 2001:407). Antropoloji, güncel sanatın ve sanat eleştirisinin gündemine bir taraftan üretim diğer taraftan tüketim bağlamında dâhil olmuştur. Bu noktada günümüz sanatının bütün yaşam alanlarını ve pratiklerini, disiplinleri sanatsal üretim-tüketim bağlamında malzemeye dönüştürmesi sanat eleştirisinin bu dönüşümü ayıklayan bir tepki geliştirmesini zorunlu kılmaktadır. Antropoloji bilgisinin sanat eleştirmenine sunduğu veriler de bu bağlamda daha anlamlı hale gelmektedir. 


\section{Sonuç}

Sanat eleştirmeni; tarih, sanat tarihi kuramları, estetik, sanat felsefesi, sanat sosyolojisi, sanat psikolojisi, mitoloji, arkeoloji ve sanat antropolojisi konularında bilgi sahibi olmalıdır ve yaptığı eleştirileri bu disiplinlerden sağladığı verilerle desteklemesi önemlidir. Sanat eleştirisinde öznel yaklaşımlardan uzaklaşmanın ya da öznel yaklaşımları kendi içinde tutarlı bir düşüncenin desteğiyle dile getirmenin önemli yollarından biri antropolojinin sunduğu imkânlardan yararlanmaktır.

Eleştiri kurumu sanat ile zanaat arasındaki farkı ortaya koyabilmek, modern sanatın beslendiği kaynaklardan biri olan zanaatın varlığını görebilmek için antropolojiye ihtiyaç duymalıdır. Zanaatın insan ve toplum ilişsisinin bir dinamiği olduğunu unutmadan ortaya çıkışını ve gelişimini anlatan antropolojinin bilgi alanına girmek zorundadır.

Antropoloji ile sanat arasındaki disiplinlerarası alanın ortaya çıkmasındaki nedenselliğin sanatın kültürün bir parçası olarak kabul edilmesiyle ilişkili olduğu unutulmalıdır. Bu bağlamda kültür kavramı ve kültürel pratikler her iki disiplinin kesiştiği noktada durur. Antropolojinin insan ve toplum arasındaki ilişkiyi gözler önüne sermek için öncelikle kültür alanlarını tercih etmesi, sanat eleştirisinin de bu alanın estetik pratiklerinden biri olan sanat eserlerini ele alma biçimini beslemektedir.

Antropoloji, sanat eleştirisinin bilimsel yapılanmasına katkı sunmaktadır. Eleştirinin kaba işçiliği yorumlamaya dayalı teknik ve terimsel yaklaşımını bilimsel ve nesnel bir bakış açısıyla tamamlayabilmek için antropolojinin verileri oldukça önemlidir. $\mathrm{Bu}$ sayede sanatın ortaya çıkardığı 'estetik' in beğeniden öte bir algıyla karşılanmasına da katk1 sunulabilir.

Son dönemlerde sanat ortamında ortaya çıkan ve tarihin, toplumun, 'öteki metinler' in iç içe geçmiş ve karmaşık yapısını çözümlemede antropolojinin önemi bir kat daha artmaktadır. Ancak sanat antropolojisinin sanat eleştirisinin yararlandı̆̆ dönüşerek sanat eleştirisini söylemden ibaret bir retoriğe dönüştürüp dönüştürmeyeceği üzerine de düşünmek gerekmektedir. Bu sorunsalın çözülmesi, ilkesel yaklaşımlar kadar sanatın ve eleştirinin takip ettiği/edeceği yola bağlı olacaktır.

Sanat eleştirisi açısından antropolojinin varlığı inkâr edilemez. Ancak yargı sanat eleştirisinde antropolojinin en önemli odak olduğuna dair bir iddiaya kadar ilerletilemez de. Antropoloji, sanat eserinin eleştirilmesinde köken, etkilenme, tarihsel ve sosyolojik etmenlerin varlığını kavrayabilmek, sanat eleştirisini de bir disipline dönüştürebilmek için gereklidir.

\section{Kaynaklar}

Baynes, K. (2002) Toplumda sanat. (Çev. Y. Atılgan), İstanbul: Yapı Kredi.

Boas, F. (2017) Antropoloji ve modern yaşam. (Çev.D. Uludağ), Ankara: Doğu Batı.

Cassirer, E. (2005) Insan üstüne bir deneme. (Çev. N. Arat), İstanbul: Say 
Erksin, G. 1994. “Antropoloji”. Bilim ve Teknik Dergisi, İstanbul: Tübitak, 320:22.

Fischer, E. (1995) Sanatın gerekliliği. (Çev. C. Çapan), İstanbul: Payel.

Gell, A. (1998) Art and agency, Oxford: Clarendon.

Güngör, A. 2013. "Antropolojinin Sanata olan etkisi ve kültürlerarası estetik üzerine düşünceler”. E-Skop Sanat Tarihi Eleştiri E-Dergisi, http://www.e-skop.com/skopbulten/ antropolojinin-sanata-olan-etkisi-ve-kulturlerarasi-estetik-uzerine dusunceler/1387, Erişim Tarihi: 21.03.2018.

Güvenç, B. (1984) Insan ve kültür. İstanbul: Remzi.

Işık, E. (2006) “Öz olarak insan ve sanat ilişkisi”. htpp://www.felsefe.gen.tr, Erişim Tarihi: 01.11 .2006$.

Kagan, M. (1993) Estetik ve sanat dersleri. (Çev. A. Çalışlar), İstanbul: İmge.

Koç, A. - M. ve A. Karoğlu. (2017) "Sanatın genişleyen sahası ve görsel etnografya". İdil Dergisi, 6/36: 2259-2272.

Kolcu, A. İ. (2010) Edebiyat kuramlarl, Erzurum: Salkımsöğüt.

Konak, A. “Antropoloji”. http://.tr.wikipedia.org/wiki/Antropoloji. Erişim Tarihi: 29.10.2006.

Lévi-Strauss, C. (2014) Modern dünyanın sorunları karşısında antropoloji. Hazırlayan: S. Kılıç, İstanbul: Metis.

Shiner, L. (2001) Sanatın icadı bir kültür tarihi. (Çev. İ. Türkmen), İstanbul: Ayrıntı.

Wells, C. 1984. Sosyal antropoloji açısından insan ve dünyası. (Çev. B. Güvenç), İstanbul: Remzi. 